\title{
Assessments of Birth Preparedness and Complication Readiness Among Women of Childbirth in Samara Logia Town, Afar, North East Ethiopia
}

\author{
Nigusie Abebaw ${ }^{1,}$, Mohammed Abdu ${ }^{1}$, Nejimu Biza ${ }^{1}$, Betel Assalfew ${ }^{2}$ \\ ${ }^{1}$ Faculty of Medical and Health Science, Samara University, Samara, Ethiopia \\ ${ }^{2}$ Faculty of Health Science, Woldeya University, Woldeya, Ethiopia \\ Email address: \\ nigusieabebaw@gmail.com (N. Abebaw),mdabdu0@gmail.com (M. Abdu), betelassalfew@yahoo.com (B. Assalfew) \\ *Corresponding author
}

\section{To cite this article:}

Nigusie Abebaw, Mohammed Abdu, Nejimu Biza, Betel Assalfew. Assessments of Birth Preparedness and Complication Readiness Among Women of Childbirth in Samara Logia Town, Afar, North East Ethiopia. American Journal of Laboratory Medicine.

Vol. 5, No. 4, 2020, pp. 95-101. doi: 10.11648/j.ajlm.20200504.13

Received: June 14, 2020; Accepted: June 28, 2020; Published: August 5, 2020

\begin{abstract}
Background: Every day thousands of women die due to obstetric complications during pregnancy and childbirth. Most of the problems are preventable. The finding showed that these deaths were high in developing countries. Based on the evidence birth preparedness and complication readiness plan is a critical strategy to, reduce maternal and newborn complications and mortalities during pregnancy and childbirth. Objective: Prevalence and associated factors of birth preparedness and complication readiness among childbirth women in Samara -Logia, Ethiopia, 2019. Method and Materials: A community-based cross-sectional study design was conducted from January 22 to April 22/ 2019. The samples were selected using a stratified sampling procedure to select the total sample size. Data were entered into Epi data version 02 and exported to SPSS Version 20 for analysis. Bi-variety and multi-variant regression were carried out to determine the associated factors and p-value $<05$ has been considered significant. Result: This finding showed that from 285 respondents $75 \%$ had ever heard about birth preparedness and complication readiness. Among the total finding, $45 \%$ of the respondents were not prepared for birth and its complications. Mothers who complain of danger signs during labor (AOR $=07$ (034-15) and partner accompany $(\mathrm{AOR}=36(27-35)$ were significantly associated with birth preparedness and complication readiness. Conclusion and Recommendation: this study identifies only $58 \%$ of women were knowledgeable about birth preparedness and complication redness. Variables having a statistically significant with birth preparedness and complication readiness were the presence of danger signs during labor and partner involvement during pregnancy. Therefore, there should be increased education, promotion of ANC, and counseling of mothers by health workers to improve their knowledge of danger signs and ANC follow up.
\end{abstract}

Keywords: Birth Preparedness and Complication Readiness, Childbirth Women, Samara-Logia

\section{Background of the Study}

Pregnancy and childbirth are threatened women's life because of obstetric complications. Yearly, global maternal deaths contribute more than half a million deaths, besides these, $99 \%$ occur in developing countries. disproportionately high burden of these deaths is occurred by developing countries $[1,2]$.

Birth-Preparedness and Complication-Readiness is a package to empower women, her family, and the community to promote maternal and neonatal survival. Ministry of Health of Ethiopia and WHO commends that pregnant women should receive focused antenatal care this is because Every pregnant woman faces the risk of sudden, unpredictable complications that could end in death or injury to herself as well as her infant. BPCR is a comprehensive matrix that includes preparing pregnant women, their families, communities, providers, facilities, and policymakers to reduce the delays that contribute to maternal and newborn 
deaths by ensuring the woman receives timely and appropriate care as well as timely preparation and rapid action [3-6].

Regardless of the great ability of Birth Preparedness and Complication Readiness in reducing the maternal and newborn deaths its reputation is not well identified in most of sub-Saharan Africa especially in Ethiopia. Birthpreparedness and complication-readiness $(\mathrm{BP} / \mathrm{CR})$ is a key tool to reduce complications and promote maternal and neonatal survival during pregnancy as well as the labor delivery period $[1,3,7,8]$.

Birth preparedness and complication readiness $(\mathrm{BP} / \mathrm{CR})$ is a wide-ranging aimed at promoting timely access to skilled maternal and neonatal services during pregnancy, delivery, and post-natal period. It encourages active preparation and decision making for delivery by pregnant women and their families $[8,9]$

A study done in Tanzania showed that Despite the ANC services, knowledge on pregnancy complications is still low and this contributes to rearrangement in looking for health care and complication redness. This tendency shows that pregnant women may be missing important packages of ANC because they lack awareness of birth preparedness and complication redness during pregnancy period. Male involvement in reproductive health during pregnancy has been encouraged for capable of the new strategy for increasing maternal and child health $[10,11]$

The safe motherhood initiative stated that skilled health professionals to assist childbirth is the most appropriate intervention to reduce maternal mortality. However, in Ethiopia according to EDHS 2011 report, only 10\% of births were attended by health professionals. This relevant decline of maternal mortality ratio and insignificant enhancement of skilled birth attendance might be due to inappropriate use of birth preparedness and complication readiness [12, 13]

Birth preparedness and complication readiness is an essential component of safe motherhood programs that encourage proper utilization of skilled maternal and neonatal care. it is also important to expand the use of skilled providers and the key intervention to minimize maternal mortality. Preparing for childbirth and its possible complications can diminish delays in seeking care. In Ethiopia, there was limited data on birth preparedness and complication readiness at the regional level, especially in the Afar regional state. Therefore, the aim of This study was to assess the status of birth preparedness and complication readiness among pregnant women in samara-logia town, afar region, Ethiopia, 2019 [14, 15]

\section{Methods and Materials}

\subsection{Study Area}

The study was conducted in Samara Logia town, Afar region which one of Agro-Pastoral community in Ethiopia. Samara is the capital city of Afar regional state located 580 $\mathrm{km}$ North- East of Addis Ababa.
Samara has a latitude and longitude of 1147 '32'N 41 0'31' E/179222 N $400861 \mathrm{E}$. At an average temperature of $33^{\circ} \mathrm{C}$.

The total population of Samara Logia town in 2016 is 29 , 72 From this, 6777 are reproductive age group women and out of this, women who had delivered in the last two years are 1375 [16].

The town has one kebele and 13 villages. Five villages are found in Samara and eight villages are found in Logia. The town has two health centers.

Study design and study period community-based crosssectional quantitative study design was conducted among child birth women from January 22 to April 22/ 2019.

\subsection{Source of Population}

The source population is all reproductive- age women who live in Samara -Logia town from January 22 to April 22/ 2019.

\subsection{Study Population}

All reproductive age women who had delivered within the last two years preceding the date of the survey in SamaraLogia town.

\subsection{Study Unit}

Reproductive age respondents who gave birth within the last two years in Samara Logia town.

\subsection{Inclusion and Exclusion Criteria}

\subsubsection{Inclusion Criteria}

All childbearing age women who gave birth during the two years before to the study in Samara Logia town.

\subsubsection{Exclusion Criteria}

Women who are not permanent residents of Samara Logia town in the period of reference. Women who were critically or mentally ill at the time of the interview

\subsection{Sample Size Determination and Sampling Technique}

The study was employed by using single population proportion sample size determination formula. Twenty three point three percent (23\%) proportion (p) of birth preparedness and complication readiness [17] with 95\% CI, and $5 \%$ marginal error (where $n$ is desired sample size, $\mathrm{Z}$ is the value of the standard normal variable at $95 \%$ confidence interval and, $p$ is proportion of Birth preparedness and complication readiness and $\mathrm{d}$ is a marginal error which is $5 \%$ ) was considered to calculate the sample size. The samples were selected using a stratified sampling procedure to select the total sample size properly, and a $10 \%$ contingency for non-respondents was also added. After all, the final sample size became 28

\subsection{Data Collection Materials and Procedures}

Data was collected by using a structured interviewer- 
administered questionnaire by four selected midwifery staff. The tool is adapted from the survey tools developed from birth preparedness and complication readiness among rural women of reproductive age in Abeshige woreda, Gurage zone, SNNPR, Ethiopia [15]. During data collection, the purpose of the study was clearly explained for respondents. Also, the right, privacy, and cultural taboos were respected. Finally, verbal consent was obtained from samara university college of medical and health science, department of midwifery.

\subsection{Variables}

\subsubsection{Dependent Variables}

Birth preparedness and complication readiness

\subsubsection{Independent Variables}

Maternal demographic characteristics

Obstetric factors

Household income

Awareness of danger signs

\subsection{Data Analysis}

The collected data were checked for its completeness and consistencies. Then, it was cleaned, coded, and entered into Epi data Version 0 and exported to statistical package for social sciences (SPSS) version 20 to identify significant association factors. First, simple frequency distribution was calculated. Multiple Logistic regression analysis was also done to identify factors associated with Birth Preparedness and Complication Readiness, the p-values $<05$ were considered to indicate statistical significance.

\subsection{Ethical Consideration}

A Formal letter of permission was obtained from Samara University College of Medical and Health Science to communicate with Samara-Logia health office administrator. The researcher informed about the aim of the study and the confidentiality of the information before reviewing the data.

\section{Results}

Socio -Demographic Characteristics of The Participants $(\mathrm{N}=285)$.

This study was conducted on a total of 285 reproductive age women those who gave birth in the last two years at Samara Logia town. Out of these, 111 (39\%) were between in the age range of 20 and 2 Majority of the participants 264 $(96 \%)$ were married. Besides these most of participants 189 $(63 \%)$ were house wives (Table 1$)$.

Table 1. Distribution of socio demographic and socio-economic variables, Samara-Logia town, May 2019.

\begin{tabular}{lll}
\hline Varible & Frequency & Percent \\
\hline Town & & \\
Logia & 251 & 81 \\
Samara & 34 & 19 \\
Age in years & & \\
\hline
\end{tabular}

\begin{tabular}{|c|c|c|}
\hline Varible & Frequency & Percent \\
\hline $15-19$ & 6 & 1 \\
\hline $20-24$ & 111 & 39 \\
\hline $25-29$ & 106 & 32 \\
\hline $30-34$ & 42 & 17 \\
\hline $35-39$ & 12 & 2 \\
\hline $40-44$ & 8 & 8 \\
\hline $45-49$ & 0 & 0 \\
\hline \multicolumn{3}{|l|}{ Marital status } \\
\hline Married & 264 & 96 \\
\hline Divorced & 14 & 9 \\
\hline Widowed & 3 & 1 \\
\hline Separated & 4 & 4 \\
\hline \multicolumn{3}{|l|}{ Religion } \\
\hline Muslim & 207 & 76 \\
\hline Orthodox & 72 & 23 \\
\hline protestant & 6 & 1 \\
\hline Total & 285 & 100 \\
\hline \multicolumn{3}{|l|}{ Ethnicity } \\
\hline Afar & 104 & 35 \\
\hline Amhara & 134 & 47 \\
\hline Tigre & 32 & 12 \\
\hline Oromo & 14 & 9 \\
\hline Others & 1 & 4 \\
\hline \multicolumn{3}{|l|}{ Occupation } \\
\hline Housewife & 189 & 63 \\
\hline Gov't employee & 23 & 1 \\
\hline Merchant & 45 & 18 \\
\hline Private employee & 6 & 1 \\
\hline Daily laborer & 20 & 7 \\
\hline \multicolumn{3}{|l|}{ Maternal educational status } \\
\hline Not able to write \&read & 27 & 76 \\
\hline Able to write \&read & 13 & 37 \\
\hline Primary Education (1-8) & 27 & 77 \\
\hline Secondary education (9-12) & 19 & 54 \\
\hline College or university & 14 & 41 \\
\hline \multicolumn{3}{|l|}{ Paternal educational status } \\
\hline Not able to write and read & 55 & 13 \\
\hline Able to write and read & 52 & 12 \\
\hline Primary education (1-8) & 39 & 17 \\
\hline Secondary education (9-12) & 51 & 19 \\
\hline College or university & 81 & 25 \\
\hline Don’t know & 4 & 4 \\
\hline \multicolumn{3}{|l|}{ Average monthly income } \\
\hline$<1000$ birr & 97 & 34 \\
\hline 1000-3000 birr & 92 & 33 \\
\hline$>3000$ birr & 87 & 35 \\
\hline Don't know & 9 & 2 \\
\hline
\end{tabular}

Obstetric Characteristics of The Respondents.

From a total of 285 reproductive age women who had delivered in the last two years, 268 (94) were found to receive $\mathrm{ANC}$, from this majority of them $223(82 \%)$ found to receive ANC within 1 to 4 months and $166(69 \%)$ of them had 2 - 3 times ANC follow up. Details are show in the table below. (Table 2).

Table 2. Obstetric characteristics of respondents in Samara- Logia town, May 2019.

\begin{tabular}{lll}
\hline Variables & Frequencies & percentage \\
\cline { 1 - 2 } Total Number of Pregnancies & 59 & 27 \\
\hline 1 & 172 & 64 \\
5 to 4 & 54 & 19 \\
Total number of deliveries & & \\
\hline
\end{tabular}




\begin{tabular}{lll}
\hline Variables & Frequencies & percentage \\
\hline Total Number of Pregnancies & 59 & 27 \\
\hline 1 & 168 & 59 \\
$2-4$ & 39 & 17 \\
5 and above & & \\
Ever had Stillbirth & 32 & 12 \\
Yes & 253 & 88 \\
No & 100 & 100 \\
Total & & \\
Received ANC & 268 & 94 \\
Yes & 17 & 6 \\
No & & \\
First ANC received (in months) n=268 & 223 & 82 \\
1-4 & 41 & 13 \\
$5-6$ & 4 & 5 \\
$>=7$ & & 63 \\
Number of ANC visits (n=268) & 175 & 37 \\
$<3$ & 93 & 5 \\
$>=4$ & & \\
Partner support during ANC & 162 & 58 \\
Yes & 123 & 42 \\
No & & \\
Any serious health problems related to & & \\
pregnancy & & \\
Yes & 94 & 33 \\
No & 191 & 67 \\
Problems experienced related to pregnancy & & \\
Vaginal bleeding & 74 & 77 \\
Sever fever & 50 & 52 \\
Absence or reduced fetal movement & 33 & 32 \\
Swollen face or hand & 12 & 18 \\
Headache / blurred vision & 26 & 27 \\
Seizure/convulsion & 3 & 2 \\
Leakage of fluid per vagina & 6 & 4 \\
Others & 4 & 3 \\
Health seeking behavior & & \\
Yes & 91 & \\
No & & \\
Final decision to assist health problems & & \\
made by & & \\
Herself & Both & \\
Her husband & & \\
\hline & & \\
\hline
\end{tabular}

Knowledge of danger Signs During Labor/Childbirth In Samara -Logia Town, 2019.

With regard to serious health problem/s that can occur during labor and child birth could endanger the life of pregnant women, greater than half of them $159(58 \%)$ were knowledgeable. Out of 159 women, 152 (96\%) mentioned vaginal bleeding, $119(78 \%)$ have mentioned placenta not delivered 30 minutes after the newborn as a danger sign.

Knowledge of danger signs during pregnancy in samara logia twon, 2019.

According to the response found from participant reproductive age women who had delivered within the last two years, two third of the participants 183 (62\%) knew about serious health problem/s that can occur during pregnancy and that could endanger the life of pregnant women. The rest of the participants 102 (38\%) don't know those signs (Table 3 ).
Table 3. Respondents knowledge about danger signs during pregnancy $(n=183)$, labor $(n=159)$ and post natal period $(n=154)$, Semera Logia, May 2019 .

\begin{tabular}{llll}
\hline \multirow{2}{*}{ Danger signs } & \multicolumn{2}{l}{ Danger signs } & \\
\cline { 2 - 4 } & $\begin{array}{l}\text { during } \\
\text { pregnancy }\end{array}$ & $\begin{array}{l}\text { during } \\
\text { Labor }\end{array}$ & Postpartum \\
\hline $\begin{array}{l}\text { Severe vaginal Bleeding } \\
\text { Severe Headache }\end{array}$ & $\begin{array}{l}175(95.6 \%) \\
\text { Blurred Vision }\end{array}$ & $152(95.6 \%)$ & $\begin{array}{l}149(96.8) \\
109(70.8)\end{array}$ \\
$\begin{array}{l}\text { Convulsion } \\
\text { Swollen Hands \& Face }\end{array}$ & $74(40.4)$ & & $67(43.5)$ \\
$\begin{array}{l}\text { Labor Lasting for }>24 \text { Hrs } \\
\text { Retained Placenta }\end{array}$ & $15(8.2 \%)$ & $38(23.9)$ & $33(21.4 \%)$ \\
$\begin{array}{l}\text { High Fever } \\
\text { Malodorous vaginal } \\
\text { discharge }\end{array}$ & $77(29.5 \%)$ & & \\
\hline
\end{tabular}

Knowledge About Danger Signs Of New Born Neonate.

From 285 respondents, 164 (55\%) stated that they knew any danger signs of new born during child birth. Out of those $12(3 \%)$ reported convulsion as danger sign \& $23(14 \%)$ have reported lethargy or loss of consciousness as danger sign (Table 4).

Table 4. Knowledge about danger signs of newborn, Samara Logia, 2019.

\begin{tabular}{lllll}
\hline \multirow{2}{*}{ Variables } & yes & \multicolumn{3}{l}{ No } \\
\cline { 2 - 5 } & Number & Percent & Number & Percent \\
\hline Any danger signs & 164 & 55 & 121 & 45 \\
Difficult/fast breathing & 123 & 75 & 41 & 25 \\
Poor sucking & 113 & 69 & 51 & 31 \\
Pus/bleeding from the cord & 96 & 55 & 68 & 45 \\
Convulsion & 12 & 3 & 152 & 97 \\
Lethargy & 23 & 14 & 141 & 86 \\
Red/swollen eye with pus & 9 & 5 & 155 & 95 \\
Failure to suck & 39 & 28 & 125 & 72 \\
\hline
\end{tabular}

Source of Information About Birth Preparedness ( $\mathrm{N}=285)$

Out of 285 respondents, 207 (72\%) stated that they heard the word birth preparedness. Out of the total respondents, $162(79 \%)$ have reported as they heard from the health professional (Figure 1).

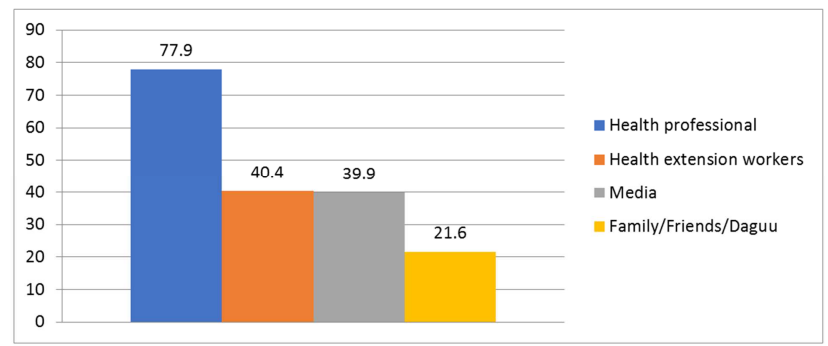

Figure 1. Source of information for BP/CR, Samara-Logia, May 2019.

Knowledge of Respondents About Preparation For Birth And Its Complication ( $\mathrm{N}=283)$.

Among 283 respondents, majority of them 208 (75\%) reported that they knew about identifying their place of birth. More than half $133(47 \%)$ of the respondents mentioned arranging means of transportation for emergency. On the other hand, it was only 17 (6\%) respondents knew to arrange compatible blood donors (Figure 2). 


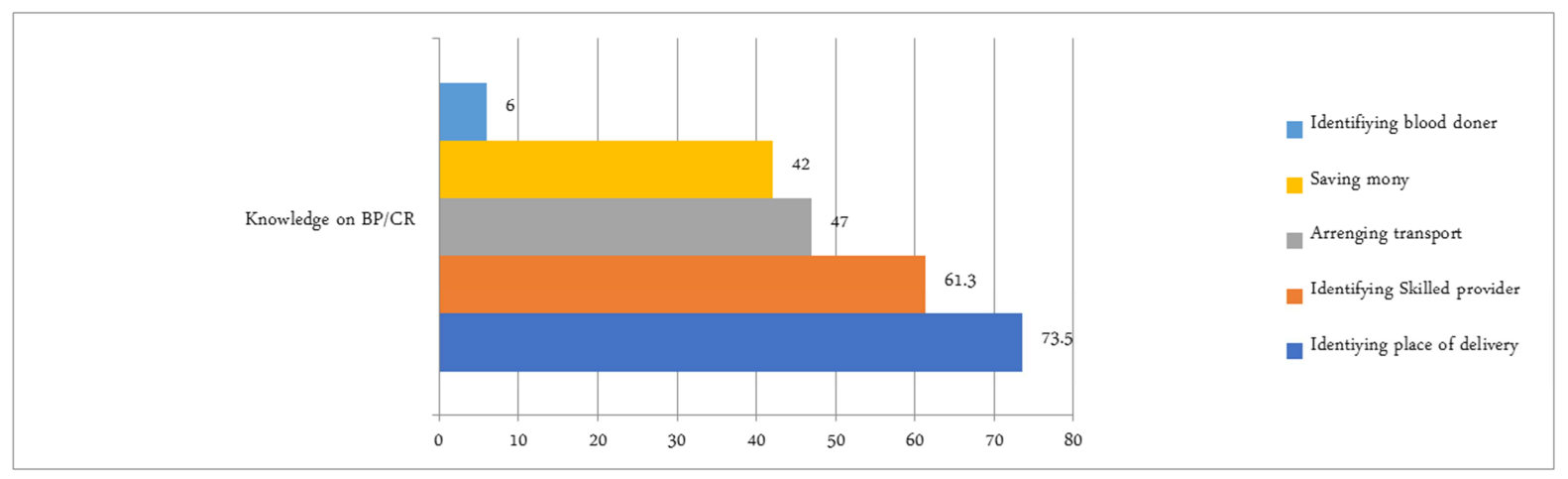

Figure 2. Knowledge of respondents about components of BP/CR, Samara- Logia, May 2019.

Prevalence of Birth preparedness and complication redness

From a total of 285 participants, $137(41 \%)$ has good knowledge about birth preparedness and complication redness, the rest 147 (56) has poor knowledge. From the total participants $124(45 \%)$ were not well prepared for birth during the last pregnancy period.

Association Factors with Their Knowledge of Birth Preparedness \& Complication Readiness, Samara -Logia Town, 2019.

In this finding Mothers who are not able to write and read were 6 times less knowledgeable about birth preparedness \& complication readiness than those who were graduates of college or university [COR=031 (623-1868 (., 95\%CI]

The study showed that the family monthly income $<1000$ birr, was two times less knowledgeable about birth preparedness and complication readiness than who got more than 3000 birrs 297 (272-151) 95\% CI]. On the other hand, Women who had no partner accompany were three times less knowledgeable than those women attend with their parents. $[\mathrm{COR}=66(225-595) 95 \% \mathrm{CI}]$. The presence of ANC follows up were also eight times more likely knowledgeable than had no ANC follow up 794 (018-16) 95\%CI.

On binary logistic regression, knowledge of danger signs during child birth/ labor, and partner accompany were found to have statistically significant association with birth preparedness and complication readiness.

Multiple logistic regression analysis was also computed to control the possible to identify confounding variables. This finding showed that knowledge about birth preparedness and complication readiness about danger signs during labor were two times more likely than who lack of knowledge about $\mathrm{BP} / \mathrm{CR}$. [AOR=071, 95\%CI (034- 15)] (Table 5).

Table 5. Association factors with their knowledge of birth preparedness \& complication readiness, samara-logia town, 2019.

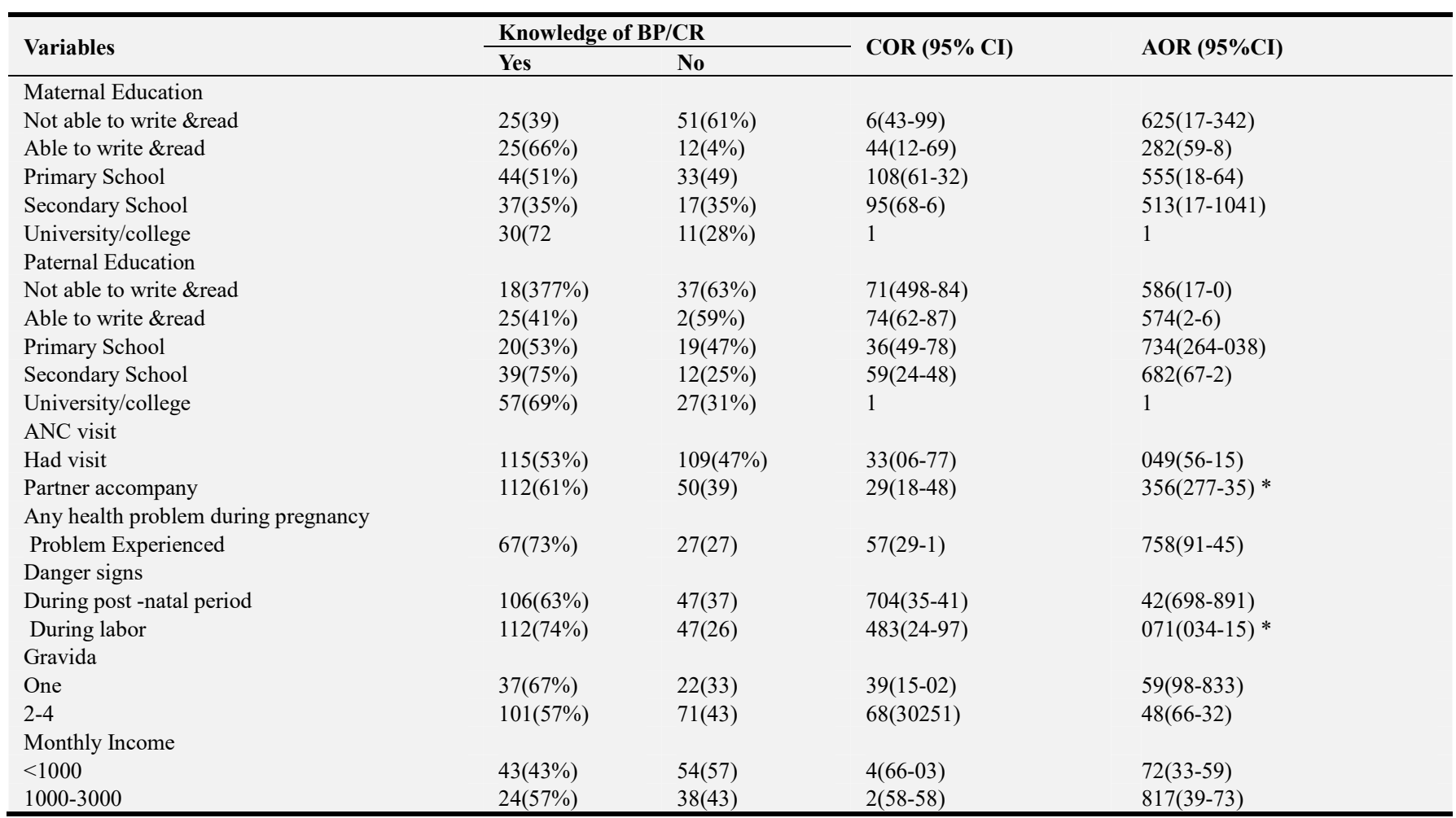

* P value less than 05 


\section{Discussion}

This study was assessed the prevalence and determinant factor of birth preparedness and complication redness plan in samara logia town among childbirth women. Currently WHO recommend that women received four ANC visit during pregnancy This study showed that the coverage of birth preparedness and complication redness plan in samara - logia town was $41 \%$. This study showed that significant number of women had less knowledge about BP/CR. This figure is less significant than study done in dire dawa city (51\%) [3] and good knowledge than study done in Goba Woreda, Oromia region (16\%) [9]. This difference could be due to the number of sample size and living style of the participants. Knowledge of the danger signs of obstetric complications is the first step to seek timely care at appropriate health facility. This study showed that participants who know about the danger sign during pregnancy were $62 \%$. This study showed that it was Slightly more than study done in Goba woreda, Oromia region 48\% [9] and Abeshinge woreda, Gourge zone 67\% [15] This is important to create sustainable mechanism to increase the maternal awareness about danger sign.

This finding showed that those women who were complain vaginal bleeding during labour/child birth were $96 \%$. this was very high compared to study done in Adigrat town, Tigray region (15\%) [5], in Goba woreda, Oromia region $11 \%$ [9], Chora district health center, western harergae $79 \%$ [17] and West Bengal, India 12\% [4]. this finding emphasized working women needs focused attention during labour and delivery period to save their life.

In the present study pregnant women who have less than three ANC checkup were more likely those women have four ANC checkup during their pregnancy period. This figure showed that women who have fourth ANC checkup were less than in Kofele district, Oromia region [2], and Nepal [14]. In this regard there was difficulty to identify late maternal danger sign. Increasing of knowledge about the benefit of $\mathrm{BP} / \mathrm{CR}$ is mandatory to reduce maternal as well as fetal complication, during pregnancy, child birth and pos -natal period.

\section{Conclusion and Recommendetion}

From 285 respondents $45 \%$ were not well prepared for birth and its complications in their last pregnancy. The study result revealed that birth preparedness and complication readiness is not well known and practiced in the study area. This is may be due to lack of knowledge about severity of danger signs of obstetric complications and about the importance of getting skilled care during pregnancy, childbirth and postnatal period even though no any health problems rose. Therefore, there should be increased education, promotion of ANC and counseling of mothers by health workers to improve their knowledge on danger signs and ANC follow up.

\section{Acknowledgements}

We would like to thanks Samara university, Afar Health bureau and Samara -logia administrative bureau to give this chance. We are also grateful for all those participating in the data collection process and we acknowledge all those who contributed to this study.

\section{Conflict of Interest}

There are no conflicts of interest in this work.

\section{Author's Contribution}

NA, MA, NB and BA: Conceived and designed the protocol as well as performed the data collection and contributed to data analysis and wrote the paper.

\section{References}

[1] Berhe AK, Muche AA, Fekadu GA, Kassa GM. Birth preparedness and complication readiness among pregnant women in Ethiopia: a systematic review and Meta-analysis. Reproductive health. 2018; 15 (1): 182.

[2] Hiluf M FMBPaCRaWiAt, North Ethiopia. Ethiop J. Health Dev. 2007, 22 (1): 14-20 Tafa, Adugna, Hailu D., Ebrahim J., Gebrie M., Wakgari N. Birth preparedness and complication readiness plan among antenatal care attendants in Kofale District, south East Ethiopia: a cross sectional survey. Diversity \& Equality in Health and Care. 2018; 15 (1): 23-9.

[3] Musa A., Amano A. Determinants of birth preparedness and complication readiness among pregnant woman attending antenatal care at Dilchora Referral Hospital, Dire Dawa City, East Ethiopia. Gynecol Obstet (Sunnyvale). 2016; 6 (2): 356.

[4] Mazumdar R., Mukhopadhyay D., Kole S., Mallik D., Sinhababu A. Status of birth preparedness and complication readiness in a rural community: a study from West Bengal, India. Al Ameen J. Med Sci. 2014; 7 (1): 52-7.

[5] Urassa DP, Pembe AB, Mganga F. Birth preparedness and complication readiness among women in Mpwapwa district, Tanzania. Tanzania journal of health research. 2012; 14 (1).

[6] Ekabua JE, Ekabua KJ, Odusolu P., Agan TU, Iklaki CU, Etokidem AJ. Awareness of birth preparedness and complication readiness in southeastern Nigeria. ISRN obstetrics and gynecology. 2011; 2011.

[7] Assessment of Magnitude and Factors Associated with Birth Preparedness and Complication Readiness Among Pregnant Women Attending Antenatal Clinic of Adama Town Health Facilities C. B., Tesfaye Y., Zelalem E., Ubong U., Kumalo A. Assessment of birth preparedness and complication readiness among pregnant mothers attending ante Natal Care Service in Mizan-Tepi University Teaching Hospital, South West Ethiopia. Clinics Mother Child Health. 2017; 14 (257): 2.

[8] Lerberg PM, Sundby J., Jammeh A., Fretheim A. Barriers to skilled birth attendance: a survey among mothers in rural Gambia. African journal of reproductive health. 2014; 18 (1): 35-43. 
[9] Markos D., Bogale D. Birth preparedness and complication readiness among women of child bearing age group in Goba woreda, Oromia region, Ethiopia. BMC pregnancy and childbirth. 2014; 14 (1): 282.

[10] Magoma M., Requejo J., Campbell O., Cousens S., Merialdi M., Filippi V. The effectiveness of birth plans in increasing use of skilled care at delivery and postnatal care in rural T. anzania: a cluster randomised trial. Tropical medicine \& international health. 2013; 18 (4): 435-43.

[11] Paulos K., Awoke N., Mekonnen B., Arba A. Male involvement in birth preparedness and complication readiness for emergency referral at Sodo town of Wolaita zone, South Ethiopia: a cross sectional study. BMC Pregnancy and Childbirth. 2020; 20 (1): 62.

[12] Iliyasu Z., Abubakar IS, Galadanci HS, Aliyu MH. Birth preparedness, complication readiness and fathers' participation in maternity care in a northern Nigerian community. African journal of reproductive health. 2010; 14 (1).

[13] Dessu S., Dawit Z., Bojola F. Assessment of birth preparedness \& complication readiness and associated factors among ANC attendant pregnant mothers in Arba Minch Town Governmental Institutions, Arba Minch, Southern Ethiopia. Int J Sex Reprod Health Care. 2019; 2 (1): 001-5.

[14] Dhakal P., Shrestha M. Knowledge on birth preparedness and complication readiness in Eastern Region of Nepal. Int J. Nurs Midwifery. 2016; 8 (10): 75-80.

[15] Zepre K. Birth Preparedness and Complication Readiness among Rural Women of Reproductive Age in Abeshige Wored Guraghe Zone, SNNPR, Ethiopia: Addis Ababa University; 2015.

[16] Sarwar MB, Samman E., Greenhill R. Good Practices for Financing Statistical Development.

[17] Regesu AH, Oda AT, Adem MK. Birth Preparedness and Complication Readiness and Associated Factors among Mothers Attending Antenatal Care at Chiro District Health Centers, West Hararge, Ethiopia. International Journal of Health Sciences and Research. 2019; 9 (4): 187-95. 